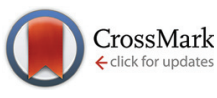

Cite this: Dalton Trans., 2016, 45, 13289

Received 21st April 2016, Accepted 10th May 2016

DOI: $10.1039 / c 6 d t 01554 a$

www.rsc.org/dalton

\section{Water oxidation catalyzed by molecular di- and nonanuclear Fe complexes: importance of a proper ligand framework $\dagger$}

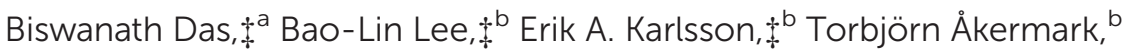 \\ Andrey Shatskiy, ${ }^{\mathrm{b}}$ Serhiy Demeshko, ${ }^{\mathrm{C}}$ Rong-Zhen Liao, ${ }^{\mathrm{d}}$ Tanja M. Laine, ${ }^{\mathrm{b}}$ \\ Matti Haukka, ${ }^{e}$ Erica Zeglio, ${ }^{f}$ Ahmed F. Abdel-Magied, ${ }^{\text {b }}$ Per E. M. Siegbahn, ${ }^{b}$ \\ Franc Meyer, ${ }^{c}$ Markus D. Kärkäs, ${ }^{* b}$ Eric V. Johnston, ${ }^{{ }^{b}}{ }^{b}$ Ebbe Nordlander ${ }^{\mathrm{a}}$ and \\ Björn Åkermark*b
}

The synthesis of two molecular iron complexes, a dinuclear iron(III,III) complex and a nonanuclear iron complex, based on the dinucleating ligand 2,2'-(2-hydroxy-5-methyl-1,3-phenylene)bis(1Hbenzo[d]imidazole-4-carboxylic acid) is described. The two iron complexes were found to drive the oxidation of water by the oneelectron oxidant $\left[R u(b p y)_{3}\right]^{3+}$.

The development of technologies to provide renewable and clean energy is one of the most important challenges of the 21st century. In fact, access to sustainable and inexpensive energy will probably become a major global problem within the next few decades. Solar energy is perhaps the most promising energy source that has the potential to satisfy the demand of present and future generations. Creating an artificial photosynthetic device would permit the conversion of solar light and water into oxygen and a storable fuel, e.g. hydrogen gas, an important complement to the generation of electricity. ${ }^{1}$

The assembly of such a device requires the combination of several complex processes: light harvesting, charge separation,

\footnotetext{
${ }^{a}$ Inorganic Chemistry Research Group, Chemical Physics, Center for Chemistry and Chemical Engineering, Lund University, PO Box 124, SE-22100 Lund, Sweden ${ }^{b}$ Department of Organic Chemistry, Arrhenius Laboratory, Stockholm University, SE-10691 Stockholm, Sweden. E-mail: markus.karkas@su.se, eric.johnston@su.se, bjorn.akermark@su.se

${ }^{c}$ Institut für Anorganische Chemie, Georg-August-Universität Göttingen, Tammannstrasse 4, D-37077 Göttingen, Germany

${ }^{d}$ Key Laboratory for Large-Format Battery Materials and System, Ministry of Education, School of Chemistry and Chemical Engineering, Huazhong University of Science and Technology, Wuhan 430074, China

${ }^{e}$ Department of Chemistry, University of Jyväskylä, PO Box 35, FI-40014 Jyväskylä, Finland

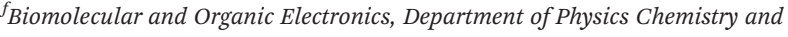
Biology, Linköping University, SE-58183 Linköping, Sweden

$\dagger$ Electronic supplementary information (ESI) available: Experimental details, including procedures, syntheses and characterization of new compounds. CCDC 966406 for iron complex 4. For ESI and crystallographic data in CIF or other electronic format see DOI: 10.1039/c6dt01554a

$\$$ These authors contributed equally to this work.
}

electron transfer, water oxidation and reduction of protons to molecular hydrogen. Currently, water oxidation is the limiting factor and the pursuit of stable and efficient water oxidation catalysts (WOCs) remains a challenge despite the considerable progress during the last years. ${ }^{2}$ Molecular WOCs offer flexibility in catalyst design and are amenable to straightforward mechanistic studies compared to their heterogeneous counterparts. The insight gained from such studies will certainly be of value for creating a better understanding of the high-valent metal species generated at surfaces in water splitting devices. ${ }^{3}$

The efforts to develop synthetic WOCs have focused on catalysts based on noble metals, such as ruthenium, ${ }^{4}$ due to their robustness. However, the scarcity of such metals might limit their use in large-scale applications and the development of WOCs comprised of abundant, inexpensive first-row transition metals is therefore of particular importance..$^{5-12}$

The dinuclear manganese(II,III) complex 1 (Fig. 1), ${ }^{13,14}$ and related manganese complexes, ${ }^{15}$ together with a similar dinuclear ruthenium complex, ${ }^{16}$ have recently been studied as potential WOCs. However, none of these complexes catalyze water oxidation using $\mathrm{Ce}^{\mathrm{IV}}$ as the chemical oxidant. It is believed that the reason is two-fold-hydrolysis of the complexes under acidic conditions and oxidation of the labile benzylic amine. It was therefore surprising that a series of iron complexes, containing ligands with benzylic amine functions, were quite efficient water oxidation catalysts, using $\mathrm{Ce}^{\mathrm{IV}}$ as oxidant, without affecting the ligand system. ${ }^{7 a-c}$

Recently, our group designed the bio-inspired ligand 2,2'(2-hydroxy-5-methyl-1,3-phenylene)bis( $1 H$-benzo[ $d]$ imidazole4-carboxylic acid) $\left(\mathrm{H}_{5} \mathrm{~L}\right)$ bearing imidazole groups in place of the benzylic amines, and negatively charged carboxylate functionalities, and reported on the synthesis of the corresponding manganese(II,III) complex 2 (Fig. 1). Complex 2 was able to catalyze the oxidation of water to molecular oxygen, thus circumventing the problematic issue with oxidative decomposition. ${ }^{10}$ 

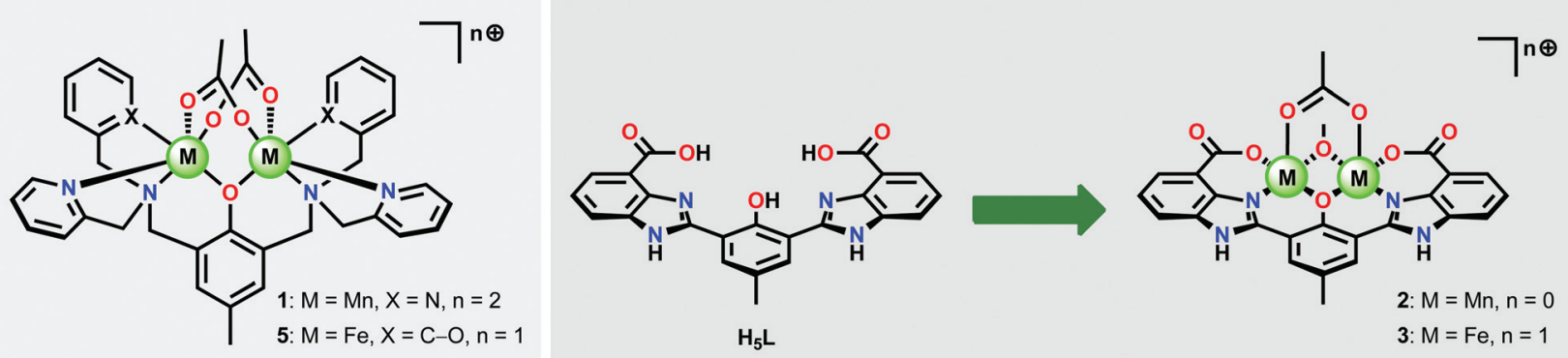

Fig. 1 Structures of dinuclear manganese complexes 1 and 2, ligand $\mathrm{H}_{5} \mathrm{~L}$, and dinuclear iron complexes 3 and 5.

The negatively charged groups have been shown to dramatically reduce the redox potentials of the metal center(s), ${ }^{16,17}$ which is required for use in a photocatalytic system with $\left[\mathrm{Ru}(\mathrm{bpy})_{3}\right]^{2+}$-type photosensitizers (bpy $=2,2^{\prime}$-bipyridine). Encouraged by these results it was decided to synthesize and study the corresponding dinuclear iron complex 3 (Fig. 1).

Herein we show that the molecular iron complex is indeed capable of catalyzing oxidation of water, when driven by mild one-electron $\left[\mathrm{Ru}(\mathrm{bpy})_{3}\right]^{3+}$-type oxidants. Attempts to grow crystals of complex 3 from DMSO for X-ray crystallography gave to our surprise the nonanuclear iron cluster $\mathbf{4}$, which was also found to be catalytically active. The bio-inspired ligand $\mathrm{H}_{5} \mathrm{~L}$ was prepared in a two-step synthetic route (Scheme S1 $\dagger$ ). The $\left[\mathrm{Fe}_{2}^{\mathrm{III}, \mathrm{III}}\left(\mathrm{H}_{2} \mathrm{~L}\right)(\mu-\mathrm{OMe})(\mathrm{OAc})\right]^{+}$complex 3 was prepared by addition of a methanolic solution of $\mathrm{Fe}\left(\mathrm{BF}_{4}\right)_{2} \cdot 6 \mathrm{H}_{2} \mathrm{O}$ (2 equiv.) to a methanol/ $\mathrm{Et}_{3} \mathrm{~N}(9: 1)$ solution containing ligand $\mathrm{H}_{5} \mathrm{~L}$ (1 equiv.) and sodium acetate ( 2 equiv.). Stirring at room temperature overnight afforded the title complex as a dark solid (see Scheme S1 and ESI $\uparrow$ for details).

Unfortunately, attempts to obtain crystals suitable for X-ray crystallography have so far failed. However, high-resolution mass spectrometry (HRMS), elemental analysis, Mössbauer spectroscopy and UV-vis spectroscopy of complex $\mathbf{3}$ are all in agreement with the suggested molecular structure (see Fig. S1S3†). The HRMS spectrum of the dinuclear iron(III,III) complex in negative mode displayed a peak at $\mathrm{m} / \mathrm{z} 624.9751$ with a characteristic isotope pattern that was assigned to the molecular ion $\left[\mathrm{Fe}_{2}^{\mathrm{III}, \mathrm{III}}(\mathrm{L})(\mathrm{OAc})(\mathrm{OMe})\right]^{-}$(see Fig. S1†). Mössbauer spectroscopy was conducted on the dinuclear complex in order to support the oxidation state and the spin state of the iron centers in complex 3 (Fig. S3†). The spectrum revealed a single doublet with an isomer shift and quadrupole splitting of $\delta=$ $0.48 \mathrm{~mm} \mathrm{~s}^{-1}$ and $\Delta E_{\mathrm{Q}}=0.89 \mathrm{~mm} \mathrm{~s}^{-1}$, respectively, which are characteristic for high-spin iron(III) species. Similar values have been found for other dinuclear and tetranuclear complexes with an $\left[\mathrm{Fe}^{\mathrm{III}} \mathrm{Fe}^{\mathrm{III}}\right]$ core. ${ }^{18 b, 19,20}$

The electrochemistry of iron complex 3 was studied in buffered aqueous solutions (phosphate buffer, $0.1 \mathrm{M}, \mathrm{pH}$ 7.2), resembling the conditions employed in the catalytic experiments (vide infra), and displayed an onset potential for electrocatalytic water oxidation at $\sim 1.25 \mathrm{~V} v$ s. the normal hydrogen electrode (NHE) (Fig. S4†). The differential pulse voltammo- gram (DPV) of complex 3 displayed two oxidation peaks in the region $0.3<E<1.3 \mathrm{~V}$ (Fig. S5 $\dagger$ ). The first peak at $0.74 \mathrm{~V}$ vs. NHE was assigned to the formal oxidation of $\mathrm{Fe}_{2}^{\text {III,III }} \rightarrow$ $\mathrm{Fe}_{2}^{\mathrm{III}, \mathrm{IV}}$ and the second one, occurring at $1.14 \mathrm{~V}$, was attributed to $\mathrm{Fe}_{2}^{\mathrm{IIIIV}} \rightarrow \mathrm{Fe}_{2}^{\mathrm{IV}, \mathrm{IV}}$. Importantly, both oxidations appear at a sufficiently low potential to be thermodynamically accessible by the $\left[\mathrm{Ru}(\mathrm{bpy})_{3}\right]^{3+}$ oxidant $\left(E_{1 / 2}=1.26 \mathrm{~V} v\right.$ s. NHE).

The catalytic activity of iron complex 3 in water oxidation was evaluated using the one-electron oxidant $\left[\mathrm{Ru}(\mathrm{bpy})_{3}\right]\left(\mathrm{PF}_{6}\right)_{3}$. When a buffered aqueous solution containing complex 3 was added to the oxidant $\left(\left[\mathrm{Ru}(\mathrm{bpy})_{3}\right]^{3+}\right)$, oxygen evolution was observed (Fig. 2a). At a concentration of $26 \mu \mathrm{M}$, a turnover number (TON) of $\sim 4$ was reached. Subsequent kinetic experiments demonstrated that the initial rates of oxygen evolution exhibited a linear dependence on the catalyst concentration, with an apparent first-order rate constant of $0.71 \mathrm{~min}^{-1}$ (Fig. 2b). These findings suggest that the rate-limiting and preceding steps of the catalytic cycle include only one molecule of the catalyst. As $\mathrm{O}-\mathrm{O}$ bond formation is typically the rate-limiting step of catalytic water oxidation, the data suggests that $\mathrm{O}-\mathrm{O}$ bond formation takes place intramolecularly through coupling of two iron-oxo units or through nucleophilic attack by water on a high-valent iron-oxo center. Photochemical experiments were subsequently carried out in a three-component system using $\left[\mathrm{Ru}(\mathrm{bpy})_{2}(\mathrm{deeb})\right]\left(\mathrm{PF}_{6}\right)_{2}$ (deeb $=$ diethyl (2,2'-bipyridine)-4,4'-dicarboxylate) as photosensitizer ( $E_{1 / 2}$ $\mathrm{Ru}^{\mathrm{III}} / \mathrm{Ru}^{\mathrm{II}}=1.40 \mathrm{~V} v$ s. NHE) and $\mathrm{Na}_{2} \mathrm{~S}_{2} \mathrm{O}_{8}$ as sacrificial electron acceptor, and showed that complex $\mathbf{3}$ is able to promote photoinduced water oxidation (Fig. S7†). The low TONs obtained in the $\mathrm{O}_{2}$ evolution experiments are probably due to a combination of the slow kinetics, low thermodynamic driving force when $\left[\mathrm{Ru}(\mathrm{bpy})_{3}\right]^{3+}$ is used as the oxidant (the redox potential of this oxidant, $E_{1 / 2}=1.26 \mathrm{~V} v \mathrm{~s}$. NHE, is essentially equal to the onset potential for electrocatalytic water oxidation mediated by complex $3, E_{\text {onset }}=\sim 1.25 \mathrm{~V} v s$. NHE), and the limited stability of the $\left[\mathrm{Ru}(\mathrm{bpy})_{3}\right]^{3+}$-type oxidants in neutral aqueous solutions, which contribute to unproductive reaction pathways.

Quantum chemical calculations were also performed on the dinuclear iron(III,III) complex 3. For the related dinuclear manganese(II,III) complex 2, it has previously been established that in aqueous phosphate buffer solutions, the bridging methoxide and acetate ligands are replaced by hydroxide and 
a)

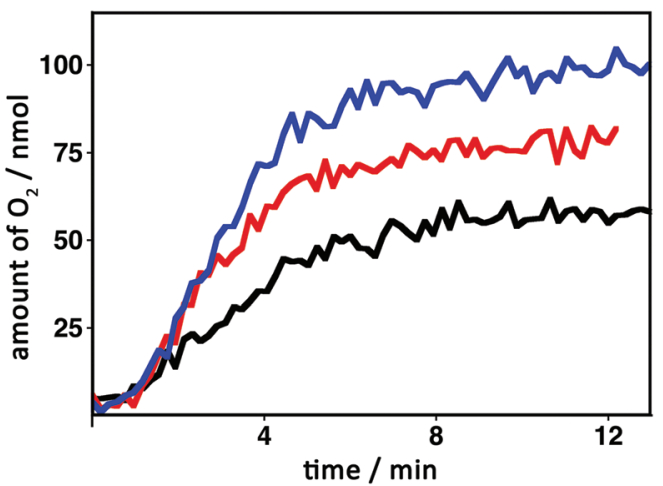

b)

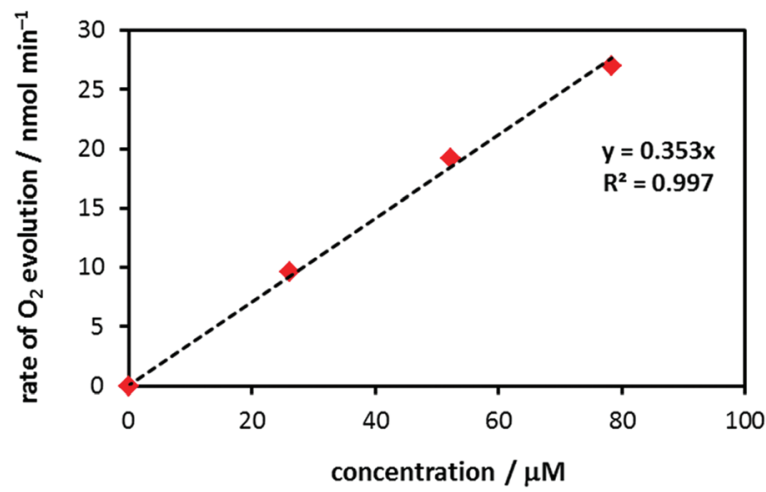

Fig. 2 (a) $\mathrm{O}_{2}$ evolution kinetics by iron complex 3 as a function of time. (b) Initial rate of oxygen evolution as a function of the concentration of catalyst 3 . The initial rates of oxygen evolution $\left(\mathrm{nmol} \mathrm{s}^{-1}\right)$ were calculated from the plot of oxygen evolution as a function of time (60-180 s). Conditions: experiments were performed by adding an aqueous phosphate buffer solution $(0.1 \mathrm{M}, \mathrm{pH} 7.2,0.5 \mathrm{~mL})$ at $20^{\circ} \mathrm{C}$ containing iron complex 3 to the chemical oxidant $\left[\mathrm{Ru}(\mathrm{bpy})_{3}\right]\left(\mathrm{PF}_{6}\right)_{3}(3.0 \mathrm{mg}, 3.0 \mu \mathrm{mol})$. Concentration of complex 3: $80 \mu \mathrm{M}(-), 52 \mu \mathrm{M}(-), 26 \mu \mathrm{M}(-)$.

phosphate ligands, respectively, which generates the catalytically active species. ${ }^{21}$ We therefore propose that under catalytic conditions iron complex 3 undergoes a similar transformation and acquires a bridging hydroxide and a phosphate ligand. Quantum chemical calculations suggest that iron complex 3 exists as three different isomers, which are shown in Fig. S9 (for a detailed discussion, see ESI $\dagger$ ).

To verify that the ligand frameworks must be resistant to oxidation if they are to promote water oxidation, the related dinuclear iron(III,III) complex $\mathbf{5}^{18 c}$ was synthesized (Fig. 1). Compared to complex $\mathbf{3}$, complex $\mathbf{5}$ is more similar to previously reported iron-based WOCs, ${ }^{7 a-c}$ since it is based on a benzylic amine ligand scaffold. However, neither with $\left[\mathrm{Ru}(\mathrm{bpy})_{3}\right]^{3+}$ (in a buffered neutral aqueous solution) nor $\mathrm{Ce}^{\mathrm{IV}}$ (in an acidic aqueous solution) as oxidants, could oxygen evolution be observed with complex 5 . The most probable explanation is that degradation of the ligand occurs, as we have previously observed with related ligands. The fact that complex 5 does not catalyze water oxidation highlights that the observed activity for the dinuclear iron complex 3 is not general and that special ligand frameworks are required to promote oxidation of water.
Further, control experiments using simple iron(II) salts, such as iron(II) chloride, in the absence of ligand $\mathrm{H}_{5} \mathrm{~L}$ gave no detectable amounts of oxygen. Omitting complex 3 resulted in decomposition of the oxidant, $\left[\mathrm{Ru}(\mathrm{bpy})_{3}\right]\left(\mathrm{PF}_{6}\right)_{3}$, without any detectable oxygen production. Finally, to demonstrate that the produced oxygen originates from water, the experiments were repeated with ${ }^{18} \mathrm{O}$-labeled water under otherwise unchanged conditions (Fig. S6 $\dagger$ ). With a relative ${ }^{18} \mathrm{O}$ concentration of $6.3 \%$, the ratio of the two isotopomers ${ }^{16,18} \mathrm{O}_{2} /{ }^{16,16} \mathrm{O}_{2}$ of the evolved oxygen was found to be close to the theoretical value for both oxygen atoms being derived from water.

We also tried to obtain single crystals of the dinuclear complex 3 for X-ray crystallography. However, the limited solubility of complex 3 in organic solvents prevented us from using common solvents such as acetonitrile, $\mathrm{MeOH}$ and $\mathrm{CH}_{2} \mathrm{Cl}_{2}$.

Attempts to crystallize the complex by dissolution in warm DMSO, followed by cooling and standing for two weeks, generated a microcrystalline precipitate. Despite the small size of the crystals, an X-ray structure could be obtained. The precipitate turned out to be the iron-oxo cluster $\left[\mathrm{Fe}_{9}\left(\mathrm{H}_{2} \mathrm{~L}\right)_{6}(\mathrm{O})_{9}\right](\mathbf{4})$, composed of nine iron atoms and six ligand molecules (Fig. 3). Each of the six peripheral iron centers is coordinated by one nitrogen atom, one phenoxy group and one carboxylate moiety from the ligand, in addition to the two carboxylates of two neighbouring ligands and one oxo-bridge to one of the three central iron ions. Each of the central iron ions in turn is linked to two peripheral and one of the central iron ions by oxo-bridges in addition to three ligand carboxylates. The catalytic effect of iron cluster 4 in water oxidation was subsequently investigated and it was found that it was capable of evolving oxygen (Fig. S8†). When using a concentration of $4.4 \mu \mathrm{M}$ of the cluster, a TON of $\sim 27$ was obtained. ${ }^{22,23}$

An important question is whether complexes $\mathbf{3}$ and $\mathbf{4}$ act as molecular catalysts or if they are merely pre-catalysts. Lau and co-workers previously reported that nonheme iron complexes decompose at neutral $\mathrm{pH}$, generating iron oxide nanoparticles, which catalyze oxygen evolution in aqueous borate buffer. ${ }^{24}$ They noted that even with a simple iron precursor, $\mathrm{Fe}\left(\mathrm{ClO}_{4}\right)_{3}$, oxygen was evolved, with a TON of $\sim 150$. However, when a

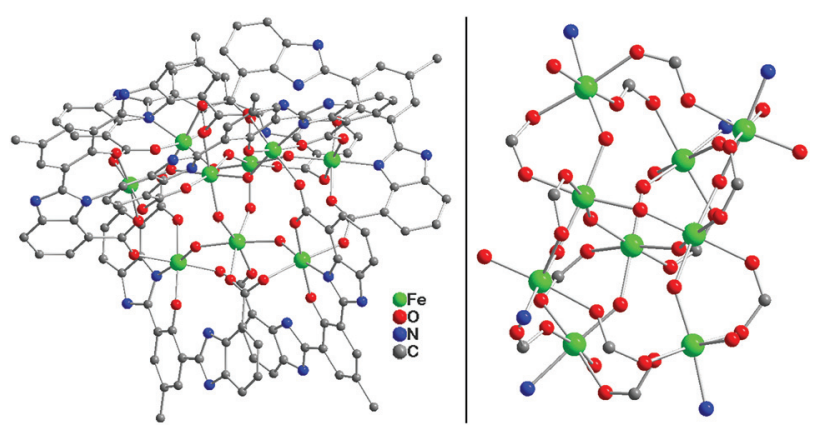

Fig. 3 (Left) Structure of the nonanuclear iron complex 4 generated from a DMSO solution of the dinuclear iron complex 3. (Right) Enlargement of the nonanuclear iron core. Hydrogen atoms have been omitted for clarity. 
phosphate buffer was used instead, no oxygen evolution was observed. Similar results were also obtained by Fukuzumi and co-workers. ${ }^{7 c}$ This dramatic difference was attributed to the formation of the insoluble $\mathrm{FePO}_{4}\left(K_{\text {sp }}=9.92 \times 10^{-29}\right)$ in phosphate buffer solutions. Since iron complexes 3 and 4 were established to be active in phosphate buffer, both complexes most likely function as molecular catalysts. This is further supported by the fact that the activity of complex 3 is about the same in borate buffer at $\mathrm{pH} 8.5$ as in phosphate buffer. Additional dynamic light scattering (DLS) experiments on iron complex 3 (Fig. S10a $\dagger$ ) and iron complex 4 (Fig. S10b $\dagger$ ) under similar conditions to $\left[\mathrm{Ru}(\mathrm{bpy})_{3}\right]^{3+}$-driven water oxidation did not reveal any nanoparticle formation (1-1000 nm) after catalysis. The low TONs are probably due to slow kinetics and the low thermodynamic driving force when $\left[\mathrm{Ru}(\mathrm{bpy})_{3}\right]^{3+}$ is used as oxidant (vide supra). In addition, ligand degradation and leaching of iron from the complex leads to the formation of insoluble iron phosphate, which is catalytically inactive.

In conclusion, we have successfully prepared a dinuclear iron complex bearing the designed ligand scaffold $\mathrm{H}_{5} \mathrm{~L}$ and demonstrated that this complex can oxidize water, when driven by $\left[\mathrm{Ru}(\mathrm{bpy})_{3}\right]^{3+}$-type oxidants. Kinetic experiments revealed a first-order dependence on the catalyst concentration, suggesting that water oxidation occurs within the two iron centers in complex 3. DLS experiments together with the observation that simple iron(II) salts do not form active catalysts in phosphate buffer solutions indicate that the catalytically active species is molecular in nature and that in situ formation of iron oxide nanoparticles does not contribute to catalysis. Furthermore, the nonanuclear iron cluster $\mathbf{4}$ was found to oxidize water with a slightly better activity than the dinuclear complex 3, illustrating that the design of higher order iron complexes housing proper ligand systems may be a viable strategy for producing more efficient iron-based catalysts for water oxidation, which is in line with a recent report on a pentanuclear iron complex. ${ }^{25}$

Financial support from the Knut and Alice Wallenberg Foundation, the Swedish Research Council (621-2013-4872), the Carl Trygger Foundation, DFG (IRTG 1422, Metal Sites in Biomolecules: Structures, Regulation and Mechanisms; see http://www.biometals.eu) and the Swedish Energy Agency, is gratefully acknowledged.

\section{Notes and references}

1 (a) N. S. Lewis and D. G. Nocera, Proc. Natl. Acad. Sci. U. S. A., 2006, 103, 15729-15735; (b) M. D. Kärkäs, E. V. Johnston, O. Verho and B. Åkermark, Acc. Chem. Res., 2014, 47, 100-111.

2 (a) M. D. Kärkäs, O. Verho, E. V. Johnston and B. Åkermark, Chem. Rev., 2014, 114, 11863-12001; (b) J. D. Blakemore, R. H. Crabtree and G. W. Brudvig, Chem. Rev., 2015, 115, 12974-13005.

3 For discussions on solar-driven water-splitting devices, see: (a) J. R. McKone, N. S. Lewis and H. B. Gray, Chem. Mater.,
2014, 26, 407-414; (b) M. S. Burke, L. J. Enman, A. S. Batchellor, S. Zou and S. W. Boettcher, Chem. Mater., 2015, 27, 7549-7558.

4 (a) Y. V. Geletii, Z. Huang, Y. Hou, D. G. Musaev, T. Lian and C. L. Hill, J. Am. Chem. Soc., 2009, 131, 7522-7523; (b) Y. Xu, A. Fischer, L. Duan, L. Tong, E. Gabrielsson, B. Åkermark and L. Sun, Angew. Chem., Int. Ed., 2010, 49, 8934-8937; (c) N. Kaveevivitchai, R. Chitta, R. Zong, M. El Ojaimi and R. P. Thummel, J. Am. Chem. Soc., 2012, 134, 10721-10724; (d) M. D. Kärkäs, T. Åkermark, E. V. Johnston, S. R. Karim, T. M. Laine, B.-L. Lee, T. Åkermark, T. Privalov and B. Åkermark, Angew. Chem., Int. Ed., 2012, 51, 11589-11593; (e) M. D. Kärkäs, T. Åkermark, H. Chen, J. Sun and B. Åkermark, Angew. Chem., Int. Ed., 2013, 52, 4189-4193; (f) S. Neudeck, S. Maji, I. Lopez, S. Meyer, F. Meyer and A. Llobet, J. Am. Chem. Soc., 2014, 136, 24-27; (g) T. M. Laine, M. D. Kärkäs, R.-Z. Liao, T. Åkermark, B.-L. Lee, E. A. Karlsson, P. E. M. Siegbahn and B. Åkermark, Chem. Commun., 2015, 51, 1862-1865; (h) A. C. Sander, S. Maji, L. Francas, T. Böhnisch, S. Dechert, A. Llobet and F. Meyer, ChemSusChem, 2015, 8, 1697-1702; (i) M. D. Kärkäs, R.-Z. Liao, T. M. Laine, T. Åkermark, S. Ghanem, P. E. M. Siegbahn and B. Åkermark, Catal. Sci. Technol., 2016, 6, 1306-1319; (j) M. D. Kärkäs and B. Åkermark, Chem. Rec., 2016, 16, 940-963.

5 (a) Q. Yin, J. M. Tan, C. Besson, Y. V. Geletii, D. G. Musaev, A. E. Kuznetsov, Z. Luo, K. I. Hardcastle and C. L. Hill, Science, 2010, 328, 342-345; (b) T. Nakazono, A. Rene Parent and K. Sakai, Chem. Commun., 2013, 49, 6325-6327; (c) B. Das, A. Orthaber, S. Ott and A. Thapper, Chem. Commun., 2015, 51, 13074-13077.

6 (a) W. C. Ellis, N. D. McDaniel, S. Bernhard and T. J. Collins, J. Am. Chem. Soc., 2010, 132, 10990-10991; (b) C. Panda, J. Debgupta, D. Díaz Díaz, K. K. Singh, S. Sen Gupta and B. B. Dhar, J. Am. Chem. Soc., 2014, 136, 1227312282; (c) R.-Z. Liao, X.-C. Li and P. E. M. Siegbahn, Eur. J. Inorg. Chem., 2014, 728-741.

7 (a) J. L. Fillol, Z. Codolà, I. Garcia-Bosch, L. Gómez, J. J. Pla and M. Costas, Nat. Chem., 2011, 3, 807-813; (b) Z. Codolà, I. Garcia-Bosch, F. Acuña-Parés, I. Prat, J. M. Luis, M. Costas and J. Lloret-Fillol, Chem. - Eur. J., 2013, 19, 8042-8047; (c) D. Hong, S. Mandal, Y. Yamada, Y.-M. Lee, W. Nam, A. Llobet and S. Fukuzumi, Inorg. Chem., 2013, 52, 9522-9531; (d) B. M. Klepser and B. M. Bartlett, J. Am. Chem. Soc., 2014, 136, 1694-1697; (e) F. Acuña-Parés, Z. Codolà, M. Costas, J. M. Luis and J. Lloret-Fillol, Chem. - Eur. J., 2014, 20, 5696-5707; (f) M. K. Coggins, M.-T. Zhang, A. K. Vannucci, C. J. Dares and T. J. Meyer, J. Am. Chem. Soc., 2014, 136, 5531-5534; (g) A. R. Parent, T. Nakazono, S. Lin, S. Utsunomiya and K. Sakai, Dalton Trans., 2014, 43, 12501-12513; (h) F. Acuña-Parés, M. Costas, J. M. Luis and J. Lloret-Fillol, Inorg. Chem., 2014, 53, 5474-5485; (i) B. Das, A. Orthaber, S. Ott and A. Thapper, ChemSusChem, DOI: 10.1002/ cssc. 201600052. 
8 (a) S. M. Barnett, K. I. Goldberg and J. M. Mayer, Nat. Chem., 2012, 4, 498-502; (b) M. K. Coggins, M.-T. Zhang, Z. Chen, N. Song and T. J. Meyer, Angew. Chem., Int. Ed., 2014, 53, 12226-12230; (c) T. Zhang, C. Wang, S. Liu, J.-L. Wang and W. Lin, J. Am. Chem. Soc., 2014, 136, 273281; (d) W.-B. Yu, Q.-Y. He, X.-F. Ma, H.-T. Shi and X. Wei, Dalton Trans., 2015, 44, 351-358.

9 (a) R. Brimblecombe, A. Koo, G. C. Dismukes, G. F. Swiegers and L. Spiccia, J. Am. Chem. Soc., 2010, 132, 2892-2894; (b) W. A. A. Arafa, M. D. Kärkäs, B.-L. Lee, T. Åkermark, R.-Z. Liao, H.-M. Berends, J. Messinger, P. E. M. Siegbahn and B. Åkermark, Phys. Chem. Chem. Phys., 2014, 16, 11950-11964; (c) E. A. Karlsson, B.-L. Lee, R.-Z. Liao, T. Åkermark, M. D. Kärkäs, V. Saavedra Becerril, P. E. M. Siegbahn, X. Zou, M. Abrahamsson and B. Åkermark, ChemPlusChem, 2014, 79, 936-950.

10 E. A. Karlsson, B.-L. Lee, T. Åkermark, E. V. Johnston, M. D. Kärkäs, J. Sun, Ö. Hansson, J.-E. Bäckvall and B. Åkermark, Angew. Chem., Int. Ed., 2011, 50, 1171511718.

11 L. Wang, L. Duan, R. B. Ambre, Q. Daniel, H. Chen, J. Sun, B. Das, A. Thapper, J. Uhlig, P. Dinér and L. Sun, J. Catal., 2016, 335, 72-78.

12 For recent reviews on earth-abundant water oxidation catalysts, see: (a) P. Du and R. Eisenberg, Energy Environ. Sci., 2012, 5, 6012-6021; (b) A. Sartorel, M. Bonchio, S. Campagna and F. Scandola, Chem. Soc. Rev., 2013, 42, 2262-2280; (c) J. R. Galán-Mascarós, ChemElectroChem, 2015, 2, 37-50; (d) A. Asraf, H. A. Younus, M. Yusubov and F. Verpoort, Catal. Sci. Technol., 2015, 5, 4901-4925; (e) M. D. Kärkäs and B. Åkermark, Dalton Trans., DOI: 10.1039/c6dt00809g.

13 P. Huang, A. Magnuson, R. Lomoth, M. Abrahamsson, M. Tamm, L. Sun, B. van Rotterdam, J. Park, L. Hammarström, B. Åkermark and S. Styring, J. Inorg. Biochem., 2002, 91, 159-172.

14 M. F. Anderlund, J. Zheng, M. Ghiladi, M. Kritikos, E. Rivière, L. Sun, J.-J. Girerd and B. Åkermark, Inorg. Chem. Commun., 2006, 9, 1195-1198.

15 P. Kurz, G. Berggren, M. F. Anderlund and S. Styring, Dalton Trans., 2007, 4258-4261.
16 B.-L. Lee, M. D. Kärkäs, E. V. Johnston, A. K. Inge, L.-H. Tran, Y. Xu, Ö. Hansson, X. Zou and B. Åkermark, Eur. J. Inorg. Chem., 2010, 5462-5470.

17 M. D. Kärkäs, E. V. Johnston, E. A. Karlsson, B.-L. Lee, T. Åkermark, M. Shariatgorji, L. Ilag, Ö. Hansson, J.-E. Bäckvall and B. Åkermark, Chem. - Eur. J., 2011, 17, 7953-7959.

18 (a) P. Gütlich, E. Bill and A. X. Trautwein, Mössbauer Spectroscopy and Transition Metal Chemistry, Springer, Heidelberg, 2011; (b) A. Stubna, D.-H. Jo, M. Costas, W. W. Brenessel, H. Andres, E. L. Bominaar, E. Münck and L. Que Jr., Inorg. Chem., 2004, 43, 3067-3079; (c) A. Neves, M. A. de Brito, I. Vencato, V. Drago, K. Griesar and W. Haase, Inorg. Chem., 1996, 35, 2360-2368.

19 A. K. Boudalis, R. E. Aston, S. J. Smith, R. E. Mirams, M. J. Riley, G. Schenk, A. G. Blackman, L. R. Hanton and L. R. Gahan, Dalton Trans., 2007, 5132-5139.

20 Y. Zang, Y. Dong, L. Que Jr., K. Kauffmann and E. Münck, J. Am. Chem. Soc., 1995, 117, 1169-1170.

21 R.-Z. Liao, M. D. Kärkäs, B.-L. Lee, B. Åkermark and P. E. M. Siegbahn, Inorg. Chem., 2015, 54, 342-351.

22 For reviews on iron-based metal-organic frameworks (MOFs) as photocatalysts for solar fuel production, see: (a) S. Wang and X. Wang, Small, 2015, 11, 3097-3112; (b) A. Dhakshinamoorthy, A. M. Asiri and H. García, Angew. Chem., Int. Ed., 2016, 55, 5414-5445; (c) Y. Li, H. Xu, S. Ouyang and J. Ye, Phys. Chem. Chem. Phys., 2016, 18, 7563-7572.

23 For recent examples of visible light-driven water oxidation catalyzed by iron-based metal-organic frameworks (MOFs), see: (a) Y. Horiuchi, T. Toyao, K. Miyahara, L. Zakary, D. D. Van, Y. Kamata, T.-H. Kim, S. W. Lee and M. Matsuoka, Chem. Commun., 2016, 52, 5190-5193; (b) L. Chi, Q. Xu, X. Liang, J. Wang and X. Su, Small, 2016, 12, 1351-1358.

24 G. Chen, L. Chen, S.-M. Ng, W.-L. Man and T.-C. Lau, Angew. Chem., Int. Ed., 2013, 52, 1789-1791.

25 M. Okamura, M. Kondo, R. Kuga, Y. Kurashige, T. Yanai, S. Hayami, V. K. K. Praneeth, M. Yoshida, K. Yoneda, S. Kawata and S. Masaoka, Nature, 2016, 530, 465468. 